\title{
Fontes digitais para a pesquisa em memória social: dois estudos de caso*
}

\section{Digital sources for research in social memory: two case studies}

\author{
Rosali Maria Nunes Henriques \\ Bacharel em História, mestre em Museologia, doutoranda em Memória Social pelo \\ PPGMS/Unirio, bolsista da Capes. Orientadora: Vera Dodebei \\ rosalih@gmail.com \\ Rafaella Prata Rabello
}

Graduanda em Letras, Bacharel em Comunicação Social, mestranda em Comunicação pelo PPGCOM/UFJF.

Orientadora: Christina Ferraz Musse

\section{Resumo}

Este texto discute como a internet, principalmente as redes sociais, tem mudado a forma como os jovens lidam com os processos da memória. Destacamos nesta comunicação os processos de lembrança e esquecimento na internet, analisando o surgimento do Facebook e como as ações de postar, curtir e compartilhar fazem parte do cotidiano dos jovens nativos digitais. Este trabalho tem como objetivo analisar o uso do $\mathrm{Fa}$ cebook como fonte de pesquisa na área de memória social em duas pesquisas distintas: a primeira delas diz respeito à memória da cidade de Juiz de Fora, MG, por meio dos registros de postagens no Grupo "Antiga Juiz de Fora", no Facebook. O segundo estudo tem como objetivo analisar o comportamento dos jovens diante dessa nova tecnologia.

Palavras-chave: Memória; Facebook; Internet; Nativos Digitais

\section{Abstract}

This paper discusses how the internet, especially social networking has changed the way of young people deal with memory processes. Featured this communication processes of remembering and forgetting on the Internet, analyzing the Facebook and how the actions of posting, enjoy and share are part of everyday life of young digital natives. This study aims to analyze the use of Facebook as a source of research in social memory in two separate surveys: the first concerns the memory of the city of Juiz de Fora, MG, through the records of posts in Group "Former Judge Out "on Facebook. The second study aims to analyze the behavior of the youth front of this new technology.

Keywords: Memory, Facebook, Internet, Digital Natives

\footnotetext{
* O trabalho foi apresentado no X Encontro Regional Sudeste - História Oral Campinas, 10 a 13 de setembro de 2013.
} 


\section{Introdução}

Procuraremos desvelar as múltiplas representações de Juiz de Fora expostas nas fotografias "postadas" pelo grupo, baseadas na memória e no imaginário das pessoas, como referências fundamentais para a habitação desta "cidade imaginária" reconstruída na rede social. Um dos objetivos da pesquisa é observar como a imagem da cidade é construída e reconstruída por meio das memórias individuais das pessoas do grupo. Para isso, devemos perceber de que modo é atribuída a identidade de Juiz de Fora ao analisarmos os comentários, os compartilhamentos, as "postagens" e as áreas de interesse dos participantes do grupo.

A segunda abordagem diz respeito ao uso do Facebook como espaço de registro da memória cotidiana pelos jovens nativos digitais. Iremos analisar como as redes sociais estão se tornando uma espécie de "lugar de memórias", incentivando a divulgação e a preservação da memória social. O principal objetivo deste estudo é discutir as relações entre a memória e a internet e entender como os nativos digitais lidam com as questões de lembrança e esquecimento na rede mundial de computadores. Ao estudar o conteúdo postado nas redes sociais, analisamos que tipo de conteúdo está sendo preservado e se o conceito de preservação poderá ser utilizado no caso das redes sociais, cujo objetivo original não é a preservação da memória, mas a convivência social entre os grupos.

\section{Memória e esquecimento na internet}

A internet tem modificado a forma como as pessoas lidam com o mundo. A evolução da internet trouxe para o ambiente acadêmico mais um desafio: a produção de fontes digitais para as pesquisas. E a memória social, tal como, em outros campos das Ciências Humanas, tem se valido das fontes digitais para o entendimento do contexto atual. Nesse caso, resta aos cientistas sociais entenderem como trabalhar metodologicamente este novo tipo de fonte. Não temos a pretensão de esgotar o assunto, mas apresentar os resultados dessas duas pesquisas efetuadas em duas instituições diferentes e em duas áreas diferentes de pós-graduação, mas que têm em comum o uso do Facebook como fonte na pesquisa de memória social.

Antes de discutirmos a relação entre memória e internet, não podemos deixar de levantar algumas questões essenciais para o campo da memória. Uma delas é a dicotomia entre lembrança e esquecimento nos processos de memória. Lembrar é também uma forma de esquecer. Em eventos traumáticos, como o Holocausto, por exemplo, o desejo de deixar registrados os fatos tais como eles aconteceram faz parte do processo de tentar esquecer o que se passou e evitar que se repitam. Primo Levi (2004) alerta para o desejo do esquecimento de muitos dos sobreviventes dos campos de concentração nazistas, no que ele denomina de memória da ofensa, no entanto, ele afirma que esta memória está sempre ancorada no contexto dos fatos e não é cópia fiel dos mesmos. Um dos riscos ao analisar as memórias de determinado autor é esperar que os fatos por ele narrados sejam cópia exata dos acontecimentos. Não se trata de reproduzir os fatos, tarefa praticamente impossível, mas lembrar do que se passou. E isso é a memória. Ela é seletiva e, portanto, como Levi mesmo afirma, falaz.

O desejo de driblar o esquecimento é o leitmotif de quem registra sua memória. Esse desejo também motiva as memórias familiares e pessoais registradas em obras, às vezes clássicas como em Marcel Proust e Pedro Nava, às vezes de forma mais rudimentar por meio de diários íntimos. Esse desejo de deixar sua memória registrada pode ter vários motivos, mas o principal deles é driblar a morte e o esquecimento. Ao deixar registrada sua memória, o homem está legando aos seus descendentes sua história, pois "Escrever é fazer recuar a morte, é dilatar o espaço da vida" (SARAMAGO, 2010: 193).

A memória não é simplesmente um mecanismo com botão de liga e desliga, que nos faz lembrar apenas do que nos interessa. Andreas Huyssen (2000) aponta que não há uma oposição entre memória e esquecimento, mas que ambas são partes do mesmo processo. Por isso, preferimos usar a expressão lembrança no lugar de memória, pois entendemos que a memória é mais ampla e abrange não somente o processo de recordação (lembrança), mas também o de esquecimento.

\section{O Facebook e as possibilidades de interação no espaço virtual}

Atualmente, podemos notar que o Facebook está se tornando uma ferramenta muito eficaz na comunicação de um determinado projeto ou grupo de trabalho. Nesse sentido, os sites e os blogs têm cada vez mais cedido espaço para as redes sociais, não só pela sua abrangência, mas pela possibilidade de interação com um maior número de pessoas. 
O fenômeno das redes sociais on-line é bem recente e nasceu de uma tendência natural do crescimento da internet em relação à criação de espaços de participação dos usuários. O Facebook foi criado em 4 de novembro de 2004 por Mark Zuckerberg e outros alunos de Harvard com objetivo de conectar estudantes dessa universidade e, posteriormente, se estendeu a outras universidades de Boston, dos EUA, Europa e finalmente se espalhou para o mundo inteiro. Possui atualmente 845 milhões de usuários ativos no mundo, sendo que 65 milhões desses usuários estão no Brasil. O Brasil é atualmente o país com o maior crescimento do Facebook, tendo atingido 30 milhões de usuários novos em $2012^{1}$. Conforme pesquisa Nielsen, divulgada em outubro de 2011, o Facebook já ultrapassou o Orkut em número de usuários no Brasil, tornando-se a rede social on-line favorita dos brasileiros.

Em setembro de 2011, o Facebook lançou uma nova versão em que o usuário cria e alimenta a sua própria linha do tempo. A ideia é criar um espaço de registro dessa memória do passado, mas também do presente. Mark Zuckerberg, criador do Facebook, durante o evento de lançamento deste novo aplicativo fez a seguinte afirmação: "Criamos um jeito de contar todas as histórias importantes de sua vida em uma única página"2. A ideia é que a vida de qualquer pessoa do Facebook possa ser disponibilizada na linha do tempo, tornando a rede social um espaço de memórias. Continua Zuckerberg: "É a história de sua vida e tem três pedaços. Seus aplicativos, suas histórias e um jeito de expressar quem você é. Queremos fazer do Timeline um lugar que você se orgulha de chamar de 'casa"'.

Ao disponibilizar esta nova versão, o Facebook assumiu um papel de aglutinador de registros das memórias das pessoas, no entanto, como em qualquer instituição ou empreendimento comercial, o objetivo inicial do Facebook não era o de suportar as memórias das pessoas, mas criar um espaço de socialização. É lícito afirmar que o Facebook está se tornando um "lugar de memórias" ou de um livro de caras (face), um livro de memórias? Segundo Marion Strecker (2012), o Facebook está se tornando uma espécie de "Catálogo da Terra Inteira" com as histórias e fotos que as pessoas vão voluntariamente alimentando na rede social. Este catálogo aglutinaria as experiências das pessoas, suas memórias e suas narrativas sobre o mundo.

Com a ajuda de seus usuários e por meio do aplicativo linha do tempo, o Facebook está adquirindo um perfil de uma grande enciclopédia de histórias e memórias, memória do momento presente e memória dos momentos passados. Seria uma espécie de museu de si mesmo. A evolução das redes sociais nesta direção era previsível, uma vez que a tendência da Web 2.0 é transformar cada pessoa em autor, criando seu próprio broadcast, tornando-se o centro de uma ferramenta de comunicação cada vez mais voltada para o indivíduo e suas individualidades. Segundo Paula Sibilia (2008), este foco no individuo e suas representações na internet teve início com os blogs, passa pelas redes sociais, mas encontra seu terreno mais fértil no Second Life 4 , no qual é possível viver uma vida completamente diferente da sua.

\section{A Juiz de Fora que habita na memória: uma cartografia sentimental da cidade}

Juiz de Fora é uma cidade que sempre teve uma veia memorialista muito forte. Pedro Nava, maior expoente do memorialismo no Brasil, nasceu na cidade e dedicou boa parte de sua obra a remontar os fragmentos de uma Juiz de Fora do seu tempo. Em sua obra, ele retrata o cotidiano e a vida da cidade do início do século XX, de uma Juiz de Fora imaginada, de ruas, casas e lugares. Para a escritora Rachel Jardim, também nascida na cidade, a memória dos cheiros e ruídos está presente nesta ressignificação imaginária da cidade.

Ao "postar" fotos antigas no Facebook, o grupo criado em torno do tema "Antiga Juiz de Fora" cria um laço comum: o da ressignificação espacial da memória da cidade, suas ruas, suas instituições e seus lugares. Tal como a Juiz de Fora que persiste na memória de Pedro Nava e de Rachel Jardim, também a Juiz de Fora presente no Facebook, é uma Juiz de Fora imaginária e imaginada. Essa memória visual e ao mesmo tempo lírica é atiçada pelas fotografias apresentadas, permitindo a manipulação e a reprodução de imagens.

Mesmo assim, a utilização do álbum atende sua finalidade tradicional: reescrever a história da cidade por meio de interações que revelam afetividades. Elas são fruto da lembrança e do esquecimento das pessoas em

1 Essas informações sobre o Facebook foram coletadas no site http://www.tecmundo.com.br/facebook/35709-brasil-foi-o-pais-com-maior-numero-de-novos-usuarios-do-facebook-em-2012.htm. Consultado em 8/6/2013.

2 Frases retiradas da fala de Zuckerberg na matéria sobre o lançamento da linha do tempo em 22 de setembro de 2011, informação disponível em Globo Tecnologia. http://g1.globo.com/tecnologia/noticia/2011/09/facebook-apresenta-linha-do-tempo-para-registrar-vida-do-usuario-no-site.html

3 Catálogo da Terra Inteira (ou “Whole Earth Catalog”) é um nome de um catálogo publicado entre os anos de 1968 e 1972 por Stewart Brand. 4 Second Life é um ambiente virtual e tridimensional, criado em 1999 e no qual as pessoas interagem através de avatares. 
relação à urbe pretérita. Os habitantes buscam encontrar no álbum as figuras, tempos e espaços que constituem a pequena história pessoal de cada membro, mas que pertencem à memória coletiva da cidade. Podemos afirmar, baseando-nos em Maffessoli (2006), que um grupo fechado age sobre o estigma de uma tribo. Dessa forma, pessoas de diferentes zonas da cidade, classes sociais, profissões, expressam sua subjetividade nesse novo território virtual. Existe um uso social da foto de reprodução eletrônica com cópias que podem ser alteradas no Photoshop.

Ao escolher trabalhar com um grupo na rede social Facebook, optamos por utilizar uma nova ferramenta de comunicação e interação entre as pessoas. Segundo dados divulgados pelo Facebook sobre sua versão brasileira, são postados ao mês 460 milhões de fotografias nessa rede social ${ }^{5}$. Esse número expressivo atenta para a necessidade de análise dos materiais expostos nesta plataforma utilizada por milhões de brasileiros. Esse álbum do grupo com imagens que constituem a identidade visual da cidade não é apenas memória, é também ruína e rastros. Os rastros são a essência da memória. E os rastros, segundo Paul Ricoeur, "estão no presente. Nenhum deles exprime ausência, muito menos anterioridade” (RICOUER, 2007: 434). No banco de imagens são resgatadas paisagens que se transformaram no passar do tempo ou não existem mais. Nessa pesquisa, nos interessa entender a dinâmica do Facebook enquanto espaço de prática social que é reflexo do cotidiano e, principalmente, como o grupo "Antiga Juiz de Fora" atua no reavivamento dessa memória sentimental da cidade de Juiz de Fora.

O sentimento memorialista de reviver uma Juiz de Fora a partir das fotografias "postadas" pelo grupo traz uma aura cultural de uma cidade que habita no imaginário de seus habitantes. Esse afeto devotado a Juiz de Fora é um signo que precisa ser decifrado, especulado, desdobrado na busca de encontrar as figuras, tempos e espaços que constituem as pequenas histórias que marcaram a cidade.

Esse boom que vem se apresentando nas redes sociais por grupos do Facebook, blogs, sites que desejam tratar do assunto revelam essa condição de angústia pela preservação da memória como resposta a aceleração do tempo, a fugacidade do contemporâneo. Guiamos a pesquisa na perspectiva de que a memória reside não apenas nos registros do passado, mas na ressignificação do presente. E que a Juiz de Fora, do grupo "Antiga Juiz de Fora”, talvez, possa ser ao mesmo tempo uma Juiz de Fora do presente, ao registrar a memória do passado.

Para analisar a concepção da memória espacial e sentimental do grupo "Antiga Juiz de Fora", a pesquisa deverá focar na coleta de informações do grupo no Facebook: fotos, datas, publicações, comentários, opção “curtir", compartilhamentos, legendas. As fotografias serão analisadas como suporte de memória. Os Estudos Culturais e da Sociologia da Cultura serão usados para interpretar as manifestações visuais e escritas do grupo, além é claro dos autores clássicos sobre a memória (já citados ao longo do texto). Será feita uma análise de conteúdo "postado" pelos membros, com o objetivo de entender as "cidades imaginadas" por cada membro do grupo.

Por questões metodológicas, iremos nos restringir a analisar as imagens históricas da cidade, desprezando quaisquer outros conteúdos que não se encaixem no perfil delimitado. Para a análise do material, vamos utilizar o programa Evernote ${ }^{6}$, um freeware que possibilita criar "clipagens" na internet. Cada "post" com fotografias antigas será "clipado" e receberá uma "tag" que permitirá agrupar por categorias, locais e sensações as "postagens". A partir do material coletado, faremos uma análise de cada tipo de conteúdo e recriaremos uma cartografia sentimental da cidade. Se necessário for, poderemos aplicar um questionário aos membros do grupo.

\section{A internet e os jovens nativos digitais}

Dentre as inúmeras possibilidades de estudar memória e internet, uma das questões que gostaríamos de abordar é a relação dos nativos digitais ${ }^{7}$ com a internet. Mas, ao discutir o uso da internet pelos nativos digitais, queremos saber como esta nova geração lida com questões como, por exemplo, preservação do patrimônio e da memória no ambiente

5 Disponível em: http://blogs.estadao.com.br/link/os-numeros-do-facebook-no-brasil/ Acesso em: 09 de set de 2012.

6 "Evernote é um conjunto de softwares e serviços projetados para tomar notas e arquivar informação na internet. A nota pode ser um pedaço de texto formatado, uma página completa ou trecho página, uma fotografia, um memorando de voz ou um manuscrito". www.wikipedia. com consultada em 21/8/2012.

7 Nativos digitais é uma expressão criada pelo educador canadense Marc Prensky (2001) para definir as pessoas que nasceram após o advento da internet, do celular e do MP3. Quem nasceu anteriormente a este período seria um imigrante digital, pois teve que aprender a lidar com esta tecnologia em sua fase adulta. Neste estudo, optamos por definir o universo de nativos digitais abrangendo jovens com idades entre 15 e 25 anos. 
virtual. O fato de dominarem uma tecnologia, muito mais que seus pais e seus professores, não significa necessariamente que dominem as discussões sobre essa mesma tecnologia. Estamos em sintonia com Livingstone (2011, 13), quando ela afirma que "dominar uma tecnologia significa manejar não só o hardware, mas tudo o que a internet oferece a seus usuários". É preciso entender os processos mentais por trás do desejo e da vontade de preservação da memória, seja na internet ou em outros espaços da vida. Assim, podemos indagar, o que essa geração pensa sobre o que deve ser preservado.

Embora o objetivo inicial da pesquisa não fosse o uso das redes sociais pelos nativos digitais, aos poucos os estudos empreendidos durante o doutorado nos levaram a querer estudar o fenômeno dessas redes sob o ponto de vista hipotético de depositárias de fragmentos de memória. A partir desse enfoque, escolhemos enfrentar a questão da efemeridade e os tempos da memória na internet como ponto de partida do meu estudo. Mas o que é efemeridade? Como se configuram os processos de lembrança e esquecimento nas redes sociais? Podemos afirmar que a memória na internet é efêmera?

Os pressupostos que movem a pesquisa são os de que as $\mathrm{TICs}^{8}$, principalmente a internet, têm mudado a forma como as pessoas se relacionam com a memória. Podemos dizer que os processos de memoração e rememoração continuam os mesmos de outros tempos, mas que hoje existem ferramentas com as quais os nativos digitais trabalham os registros de memória na internet e que modificam os tempos da memória. As narrativas de memória sempre foram sobre um passado, a partir de um presente e para um determinado futuro, pois, segundo Walter Benjamin (1994: 211), "A reminiscência funda a cadeia da tradição, que transmite os acontecimentos de geração em geração". Desde os mais primitivos tempos, passando pelos griots ${ }^{9}$, pela tradição oral, pela história oral ou em diários de meninas, as narrativas de memória foram sempre na perspectiva do presente, com a reflexão de algo que já passou e com o objetivo de trazer alguma lição para o futuro, no entanto, acreditamos que o uso da internet, principalmente das redes sociais, tem modificado a forma como o registro da memória é feito pelos nativos digitais. Ao postar fotos e textos em tempo real no Facebook, os usuários da internet estão produzindo registros e postando-os no momento exato da produção do fato. Assim, torna-se um registro sobre o momento instantâneo para um presente também instantâneo, quase como um presente-passado e um presente-presente, que podemos chamar de atual. Essa memória do presente é uma memória efêmera e imediata, compartilhada em tempo real com seus amigos e familiares. Esta, que podemos chamar de memória compartilhada, seria uma espécie de memória imediata e, ao mesmo tempo mediada pelo espaço virtual da internet, o ciberespaço. Nesse sentido, Canavilhas (2004) aponta que a internet comprime o tempo, não o tempo entre emissão e recepção da mensagem, mas o tempo da memória. Este autor afirma que desta forma, passamos a ter um passado-presente e um presente-presente.

Para a realização da pesquisa sobre memória dos jovens nativos digitais no Facebook, optamos por criar uma metodologia de coleta de dados utilizando o conteúdo postado nesta rede, uma vez que o nosso objeto empírico são as redes sociais e suas especificidades. Assim, surgiu a ideia de produzir um piloto com um grupo de jovens com o objetivo de entender o universo dos nativos digitais a partir de suas postagens no Facebook. O primeiro passo foi convidar amigos do nosso círculo social no Facebook para indicar jovens com o perfil selecionado, no entanto, esta primeira abordagem não obteve resultados satisfatórios, pois apenas três pessoas responderam ao apelo. A segunda abordagem foi mais direta. Entramos em contato por mensagem pelo próprio Facebook com jovens de nosso círculo social, para convidá-los diretamente e aos seus amigos, ao mesmo tempo em que conversávamos com colegas para indicar seus filhos e sobrinhos para participarem da pesquisa.

Para a apresentação desse projeto, selecionamos 31 jovens com idades entre 15 e 25 anos e produzimos um piloto durante o mês de março de 2012. Para realização do piloto, a escolha desses jovens obedeceu a três critérios básicos: possuir idades entre 15 e 25 anos, ter perfil no Facebook e ser ativo nessa rede social. No caso da pesquisa, era necessário que este jovem fosse bem ativo, ou seja, que postasse comentários, textos e fotos na rede social, uma vez que somente por meio desse material seria possível uma análise do conteúdo compartilhado. Embora uma grande parcela de jovens possua perfil, muitos deles não têm uma postura ativa na rede. Nesse caso, a análise do conteúdo ficaria prejudicada devido à escassez de dados. Algumas técnicas estatísticas foram aplicadas para definir os grupos analisados. A análise fatorial foi utilizada para determinar variáveis (fatores) conceituais a partir de algumas opiniões mensuradas sobre a internet e o Facebook. E, finalmente, foram

8 Tecnologias de Informação e Comunicação.

9 Griots são os contadores de histórias, geralmente idosos, nas culturas tradicionais africanas. 
criados grupos (segmentos) de usuários a partir de fatores usando a análise de agrupamento (clusters). (HAIR et al, 2005).

O processo de pesquisa teve continuidade com este mesmo grupo de 31 jovens com idades entre 15 e 25 anos no Facebook, no período de outubro a dezembro de 2012. Por se tratar de um universo muito grande de usuários, mas também por possuir características bem específicas, estabelecemos que deveríamos estudar apenas jovens brasileiros. Esta observação virtual ou acompanhamento virtual será feita diariamente e terá como objetivo analisar cada tipo de conteúdo postado.

Esta pesquisa encontra-se atualmente em fase de processamento dos dados coletados. Para a coleta dos dados, utilizamos dois tipos de ferramentas, para dois tipos diferentes de estratégias: uma primeira estratégia é contabilizar o tipo de informação postada na rede social Facebook com vistas a analisar o fluxo e a frequência das postagens. Para isso, foram preenchidos formulários do programa Microsoft Excel com os códigos estabelecidos em uma tabela por tipo, formato e assunto e posteriormente proceder à análise estatística do material, tal como fizemos no projeto piloto. A segunda estratégia tem como objetivo entender o universo do material postado na rede Facebook e se debruçou sobre o conteúdo propriamente dito. Para isso, utilizamos o aplicativo Evernote. Lançado em 2008, este aplicativo permite salvar conteúdos de sites e organizá-los por notas ou assuntos. Cada postagem efetuada por um dos 31 jovens nativos digitais escolhidos para a pesquisa foi devidamente arquivada e categorizada no aplicativo e poderá ser acessada por meio de buscas pelas anotações. O uso desse aplicativo irá facilitar a análise do material, uma vez que a organização da informação no Facebook não permite a busca por tipo de conteúdo. Ao finalizar o processo de coleta do material, iremos analisar o conteúdo postado por cada jovem, estudando o tipo de postagem e a postura do mesmo diante do Facebook. Para cada jovem pesquisado, deveremos produzir um dossiê digital, que servirá para explicitar o papel da memória no âmbito da internet.

\section{Considerações Finais}

A internet é uma realidade ainda nova em termos históricos e, por isso, a metodologia para trabalhar conteúdos nessa ferramenta também deverá ser nova. Como em qualquer pesquisa nas Ciências Humanas, também no campo da Memória Social, o objeto a ser pesquisado deve ser construído pelo pesquisador. E como se tratam de novas ferramentas de comunicação, é necessária a construção de uma metodologia que torne elucidativo o material coletado, pois conforme nos alerta Vigotski (2007, p. 59), "qualquer abordagem fundamentalmente nova de um problema científico leva, inevitavelmente, a novos métodos de investigação e análise". E a construção de um objeto de pesquisa pressupõe a pesquisa em documentos que possam comprovar ou refutar a hipótese sugerida no escopo do trabalho.

Embora ambas pesquisas se encontrem ainda em andamento, podemos tirar algumas conclusões sobre o uso de fontes digitais para pesquisas em memória. A primeira delas diz respeito à própria metodologia de pesquisa, ainda de certa forma, em estado de experimentação. Conhecida como netnografia, o uso de técnicas e métodos tradicionais da pesquisa de campo, adaptadas às fontes digitais ainda é recente e carece de bibliografia. No primeiro caso, o Facebook não será a única fonte e, portanto, deverão ser utilizados outros tipos de fontes complementares, tais como metodologia de história oral e diários de campos, que muito nos auxiliarão na análise do objeto empírico escolhido. No caso da segunda pesquisa, a grande questão reside no fato de que o próprio uso do Facebook é o objeto de estudo. Nesse caso, uma simples coleta de informações, sem uma análise do conteúdo postado, pode ser superficial e leviana, uma vez que os hábitos e os costumes de uso do Facebook poderão levar a análises equivocadas. A segunda questão diz respeito ao conceito de narrativas e suas relações com o espaço virtual da internet. Analisar este conceito torna imprescindível para quem trabalha utilizando a internet como fonte de pesquisa.

\section{Referências bibliográficas}

BENJAMIN, Walter. A obra de arte na era da sua reprodutibilidade técnica. In: Magia e técnica, arte e política. Obras escolhidas vol.1. São Paulo, Brasiliense, 1994. 
CANAVILHAS, João. A internet como memória. BOCC: Biblioteca Online de Ciências da Comunicação. 2004 http://bocc.ubi.pt/pag/canavilhas-joao-internet-como-memoria.pdf. Consultada em 08/06/2013.

HAIR JR, Joseph et al. Análise multivariada de dados. 5 ed. Porto Alegre: Bookman, 2005.

HUYSSEN, Andreas. Seduzidos pela memória. Rio de Janeiro: Aeroplano, 2000.

LEVI, Primo. Os afogados e os sobreviventes: os delitos, os castigos, as penas, as impunidades. $2^{\mathrm{a}}$ ed. São Paulo: Paz e Terra, 2004.

LIVINGSTONE, Sonia. Internet literacy: a negociação dos jovens com as novas oportunidades on-line. Matrizes. ano 4 - $\mathrm{n}^{\circ} 2$ jan./jun. 2011 - São Paulo - Brasil pp-11-42

MAFFESOLI, Michel. O tempo das tribos: o declínio do individualismo nas sociedades pós-modernas. Rio de Janeiro: Forense Universitária. 4a ed. 2006.

PRENSKY, Marc. Digital Natives, Digital Immigrants. In: MCB University Press, Vol. 9 No. 5, October 2001. Disponível em: http:/ / www.marcprensky.com/writing/Prensky\%20-\%20Digital\%20Natives, $\% 20$ Digital\%20Immigrants\%20-\%20Part1.pdf consultada em 08/06/2013.

RICOUER, Paul. A memória, a História, o esquecimento. Campinas: Unicamp, 2007.

SARAMAGO, José. Entrevista A Capital, Lisboa, 1995. In: AGUILLERA, Fernando Gómez (org). As palavras de Saramago. São Paulo: Companhia das Letras, 2010.

SIBILLA, Paula. O show do eu: a intimidade como espetáculo. Rio de Janeiro: Nova Fronteira, 2008.

STRECKER, Marion. Novo 'Catálogo da Terra inteira', Facebook faz das pessoas marqueteiros de si mesmos . Disponível em http://tecnologia.uol.com.br/noticias/redacao/2012/05/18/novo-catalogo-da-terra-inteira-facebook-transforma-pessoas-em-marqueteiros-de-si-mesmos.htm Consultado em 08/02/2013.

VIGOTSKI, Lev. A Formação Social da Mente. São Paulo: Martins Fontes, 2007.

GLOBO TECNOLOGIA. http://g1.globo.com/tecnologia/noticia/2011/09/facebook-apresenta-linha-do-tempo-para-registrar-vida-do-usuario-no-site.html consultada em 08/06/2013. 